\title{
A FORMAÇÃO DE PROFESSORES PARA O USO DAS TECNOLOGIAS: UM MOSAICO DE CONCEPÇÕES E EMOÇÕES
}

\author{
Dra. Daniela Karine Ramos - Universidade Regional de Blumenau - \\ dadaniela@gmail.com
}

\section{Resumo}

Neste artigo são apresentados aspectos relacionados à formação de professores para o uso de tecnologias nos processos de ensinar e aprender, a partir da investigação e discussão das concepções, usos, contribuições e dificuldades, no que diz respeito à inserção e ao uso das tecnologias na escola, bem como emoções e sentimentos relacionados ao uso do computador. Esses aspectos foram investigados no decorrer da disciplina de Tecnologia Educacional e Aprendizagem, oferecida no Curso de Pedagogia, na Universidade Regional de Blumenau, fazendo uso de discussões, observações e aplicação de questionários. O problema norteador dessa pesquisa é: de que forma os professores em formação compreendem e se relacionam com a tecnologia? Nesse sentido, apontamos que o estudo das tecnologias e o uso desse recurso na formação favorecem a inserção das tecnologias na educação, consequentemente oferecem instrumentos para que a escola responda aos desafios lançados pelos avanços tecnológicos e sua inserção na sociedade.

Palavras-chave: Formação de professores; Tecnologias; Emoções

\begin{abstract}
In this article is presented aspects related to the formation of the professors for the use of technologies in the processes to teach and to learn, from the inquiry and discussion of the conceptions, uses, contributions and difficulties, in respect to the insertion and the use of technologies in the school, as well as, emotions and feelings related to the use of computer. These aspects had been investigated in elapsing of discipline of Educational Technology and Learning, offered in the Course of Pedagogy, in the Universidade Regional de Blumenau, making use of discussions, comments and application of questionnaires. The guide problem of this research is: what ways the professors in formation understand the technology and what relationship they have with the technology? In this direction, we point that the study of the technologies and the use of this resource in the formation, favor the insertion of the technologies in the education, consequently offer instruments to the school answers the challenges launched for the technological advances and its insertion in the society.

Keywords: Formation of professors; Technologies; Emotions

\section{Introdução}

Neste artigo propõe-se a reflexão sobre a formação de professores para o uso de tecnologias nos processos de ensinar e aprender, a partir da investigação de aspectos relacionados a concepções, usos, dificuldades, emoções e sentimentos de professores e futuros professores em processo de formação superior.

Parte-se do entendimento de que as tecnologias são ferramentas que ampliam nossos limites, como o computador que amplia nossa capacidade de armazenamento de informações, e, também, contribui com a modificação do nosso modo de raciocinar, atuar e pensar o mundo. Muitos adolescentes da geração digital, termo utilizado por Tascoptt (1999), crescem inseridos nesse contexto de tecnologias digitais, desenvolvendo formas diferenciadas de racionar e pensar. Além disso, essa geração passa a conhecer o mundo a partir do acesso à Internet que lhes possibilita romper
\end{abstract}


barreiras geográficas, acessando informações de lugares muito distantes e estabelecendo relações com pessoas de todo o mundo.

Destaca-se, também, que as tecnologias agregam socialmente significados e sentidos, que criam categorias como incluídos e excluídos digitalmente e valorizam o domínio dos recursos tecnológicos.

Assim, esses aspectos tornam relevante a discussão sobre a tecnologia e sobre sua inserção nos espaços escolares, principalmente porque a inserção dessas ferramentas produz consequências tanto para a formação dos professores e para a prática docente, quanto para os processos de ensinar e aprender.

É diante disso que se propõe a discussão e a reflexão a partir do entendimento que as alunas do curso de Pedagogia possuem sobre a tecnologia, o modo como utilizam, introduzem nas suas práticas e se relacionam com o computador.

\section{Os percursos da pesquisa realizada}

A pesquisa foi desenvolvida no decorrer da disciplina de Tecnologia Educacional e Aprendizagem, ministrada no segundo semestre de 2005, fazendo uso de discussões, investigações e aplicação de questionários. A pesquisa foi realizada em uma turma de quarta fase do curso de Pedagogia, da Universidade Regional de Blumenau, localizada na cidade de Blumenau, em Santa Catarina, com 27 alunas.

A pesquisa realizada utiliza a abordagem qualitativa, pois concebe a realidade como a relação dinâmica entre o sujeito e o mundo. Desse modo, as observações foram realizadas no ambiente natural, no qual o fenômeno investigado ocorria, por um longo período de tempo, o que é indicado por Cozby (2003) para compreender como as pessoas se comportam no ambiente social e cultural em que vivem e investigar ambientes sociais mais complexos.

Além disso, levando-se em conta a relação estabelecida entre pesquisador e objeto ou campo de pesquisa, pode-se caracterizar como pesquisa-participante o processo de investigação desenvolvido. Tendo em vista que o pesquisador era $o$ professor da disciplina e o propositor das atividades desenvolvidas.

Nesse sentido, destacamos que o observador participante assumiu um papel ativo no ambiente investigativo, o que permitiu "observar a situação "de dentro", o pesquisador pode experienciar eventos da mesma forma que os participantes naturais" (COZBY, 2003, p. 125), utilizando diferentes técnicas como: a observação dos sujeitos e eventos, a realização de entrevistas e a análise de documentos.

A partir dessa metodologia foi possível compreender o espaço de sala de aula e a relação dos sujeitos com a tecnologia. Além disso, possibilitou estudar um contexto concreto, que envolve as condições e os resultados da experiência, possibilitando a construção de conhecimento voltado à prática. Nessa perspectiva de pesquisa 0 conhecimento teórico é valorizado, porém outras instâncias, tais como sociais, históricas e emocionais também são consideradas importantes. Diante desses aspectos, esse tipo de pesquisa valoriza a prática profissional diária, tendo em vista que esta ganha relevância ao tornar-se objeto de pesquisa.

Dessa forma, após a identificação do problema a partir das discussões em sala, como resistências para o uso do computador, pré-concepções acerca da impossibilidade de seu de uso por carências infraestruturais nas escolas, certa aversão ao uso das tecnologias por falta de habilidades técnicas e conhecimento sobre os recursos de algumas alunas, estratégias foram sendo criadas e atividades propostas para que o contato das alunas com o computador fosse alterando as pré-concepções e gerando sentimentos e emoções positivas para facilitar o posterior uso da tecnologia na prática docente nas escolas. 
Ao longo do semestre foram criadas estratégias e atividades que envolveram o uso dos recursos computacionais e sua compreensão, tais como:

a) Pesquisa em escolas da região, públicas e particulares, sobre a infraestrutura, a formação dos professores para o uso dos recursos, as concepções acerca da tecnologia educacional na perspectiva de gestores, professores e alunos;

b) Construção e utilização de blogs na web, para postagem de atividades, interação e criação de um jornal on-line;

c) Estudo e desenvolvimento de WebQuests, o que envolveu a proposição de uma situação-problema, a organização da WebQuest e a busca de sites de referência para pesquisa,

d) Gravação de jingles e spots sobre determinada temática, utilizando um software gratuito para gravação no formato MP3 e posterior publicação na web;

e) Construção de uma homepage, utilizando um site de hospedagem gratuita, para publicação da WebQuest criada;

f) Uso efetivo do ambiente virtual de aprendizagem disponível na instituição para apoio ao ensino presencial, para disponibilização de materiais, realização de discussões no fórum, indicação de sites e envio de avisos.

Assim, pontuam-se elementos importantes para a reflexão sobre a formação dos professores para o uso das tecnologias nos espaços educacionais, no que diz respeito a crenças e pré-conceitos existentes que precisam ser trabalhados em disciplinas que se propõem a atuar com a inserção das tecnologias na educação.

Diante disso, o problema norteador desta pesquisa é: de que forma os professores em formação compreendem e se relacionam com a tecnologia?

\section{Tecnologias: conceitos e concepções}

A preocupação com a formação dos professores para o uso das tecnologias na educação, nos convida a inicialmente explorar a compreensão do conceito de tecnologia, importante para a formação do professor, tendo em vista a comum associação entre tecnologia e os recursos eletrônicos modernos.

O conceito de tecnologia segundo Leite (2002) refere-se ao

acervo cultural de um povo e, como tal, se nutre das contribuições permanentes da comunidade social, em espaço, tempo e condições econômicas, políticas e sociais determinadas. A tecnologia existe como conhecimento acumulado, é produção constante e dinâmica.

Desse modo, destaca-se que principalmente os benefícios que o uso da tecnologia proporciona precisam ser cada vez mais difundidos, sobretudo por ampliarem as limitações humanas e oferecerem facilidades para a vida cotidiana. Enquanto ampliação das limitações há exemplos como: o binóculo que amplia a capacidade de visão, a tesoura que amplia as capacidades manuais, a escada que amplia o alcance humano, entre muito outros instrumentos ou tecnologias utilizados.

Esta ideia de instrumentos que ampliam a capacidade humana é discutida por Vygostsky que entende os instrumentos como mediadores. Vygotsky (1998) distinguiu dois tipos de mediadores: os instrumentos e os signos. O instrumento seria o elemento intermediário entre o homem e o objeto de seu trabalho. O signo de forma análoga ao instrumento está envolvido na atividade psicológica, como na atividade de memória e atenção. 
Pensando no uso de instrumentos, considerados tecnologias, que podem ser mediadores do processo de construção do conhecimento nos espaços educacionais, podemos adjetivar a tecnologia como educacional. Segundo Cysneiro (2000, s/n):

tecnologia educacional deve envolver algum tipo de objeto material, que faça parte de alguma práxis educativa, portanto relativa a processos de ensino e de aprendizagem, havendo algum tipo de relação entre o educador (em sentido amplo ou restrito) e a tecnologia, ou entre o aprendiz e a tecnologia.

Explorando esse conceito em sala, no início do semestre, muitas alunas compreendiam a tecnologia como um recurso eletrônico, associando-o principalmente ao computador e não consideravam o quadro negro e o giz como uma tecnologia. Outras alunas concebiam a tecnologia como um recurso tecnológico avançado, um exemplo relatado por uma delas é que "quando lançam um novo fogão, o velho deixa de ser tecnologia".

Nesse sentido, identificamos que há uma confusão relacionada ao conceito de tecnologia e a estratégia que passa, então, a ser estrutura, envolve a discussão, a leitura e a troca de informações para redefinir o conceito.

Outro aspecto investigado com relação à concepção de tecnologia é sua relação com as crenças e valores. Tendo em vista que ainda hoje podemos identificar uma visão maniqueísta de certo ou errado e de bom ou mal.

$\mathrm{Na}$ turma de pedagogia $95,5 \%$ das alunas consideram o computador como algo bom, principalmente pelas contribuições oferecidas relacionadas com a rapidez na busca de informações, possibilidade de contato com o mundo, ao conforto, ao acesso à informação, com as facilidades oferecidas para execução de determinadas tarefas, as alternativas para a comunicação e para a troca de ideias.

Segundo uma das alunas o computador é bom "porque é uma ferramenta que nos dá oportunidade de se conectar com o mundo, ampliando a capacidade de adquirir conhecimento".

Por outro lado, a aluna que considera o computador como algo ruim, justifica sua postura pelo fato do computador, segundo ela, ser de difícil utilização.

Estes julgamentos relacionam-se com a percepção que o sujeito tem sobre o computador, os quais por sua vez, relacionam-se, com as experiências, conhecimentos, habilidades e interesses, e podem favorecer a ampliação de alguns aspectos em detrimento a outros. Segundo Cysneiros (2000) "quando usamos um instrumento (uma tecnologia), ocorre uma seleção de partes do objeto conhecido através dele, resultando em ampliação de alguns aspectos e redução de outros". podemos

No que diz respeito à visão maniqueísta, Dias (1999, p.276) afirma que

generalizar dizendo que as tecnologias, por si mesmas, não determinam nada; não são boas, nem más. Essa visão maniqueísta de identificar as novas tecnologias como causas do mal contemporâneo, compartilhada por alguns autores, é muito simplista e tendenciosa.

Essa classificação do modo como foi apresentada pela alunas está relacionada à significação atribuída por elas, relacionadas com as experiências e conhecimentos que elas têm sobre a tecnologia.

De fato não chegaríamos a uma resposta única, a tecnologia é boa ou a tecnologia é ruim, tendo em vista que essa é uma análise complexa que envolve sobretudo a investigação do modo como a mesma é utilizada e para que é utilizada, merecendo, também, uma análise do contexto social e cultural na qual se insere e as relações que são estabelecidas com ela. 
Quando utilizada na educação a tecnologia, do mesmo modo, está intrinsecamente relacionada ao modo como é utilizada. Diante disso, para ampliar a compreensão das possibilidades do uso das tecnologias na escola e desconstruir a ideia de que não adiantava aprender a usar o computador porque na escola há muitos problemas de infraestrutura, foi proposta uma investigação nas escolas da região nas quais as alunas tinham acesso, como as escolas em que trabalhavam, as escolas próximas de suas residências ou as escolas em que os filhos estudavam.

Nessa investigação foram entrevistados um gestor, dois professores e cinco crianças, a partir de um questionário definido, acerca das concepções sobre o computador e a internet e os modos como eram utilizados.

Os resultados foram compartilhados em sala de aula e como tínhamos um universo que incluía escolas públicas e particulares, que tinham laboratório de informática ou não, escolas que tinham e não usavam, entre outras situações, as quais configuraram-se como informações para modificar as pré-concepções.

Dentre os relatos apresentados destaca-se o de uma escola equipada com laboratório com vinte e cinco computadores que eram utilizados de modo restrito para não estragar as máquinas, enquanto outro relato descreve uma escola com apenas dois computadores para a secretaria, a qual havia cedido um deles para o uso dos professores e alunos nas atividades escolares; como exemplos de atividades são citadas: a exploração da escrita na tela e os ícones do computador.

As duas situações demonstram que há diferentes posturas para lidar com as dificuldades relacionadas à infraestrutura.

\section{A formação dos professores para o uso do computador}

A inserção do computador na escola para prover aprendizagem sugere mudanças pedagógicas que englobam a organização da escola, a dinâmica da sala de aula, o papel do professor e dos alunos e a relação com o conhecimento. É necessária uma reestruturação do ensino, não só na sua estrutura física e metodologia, bem como nas interrelações, o que demanda uma nova postura profissional dos professores e um repensar dos processos educacionais, principalmente aqueles relacionados com a formação de profissionais e com os processos de aprendizagem.

$\mathrm{Na}$ turma de pedagogia pesquisada, todas as alunas de algum modo utilizam o computador e a frequência de uso é a seguinte:

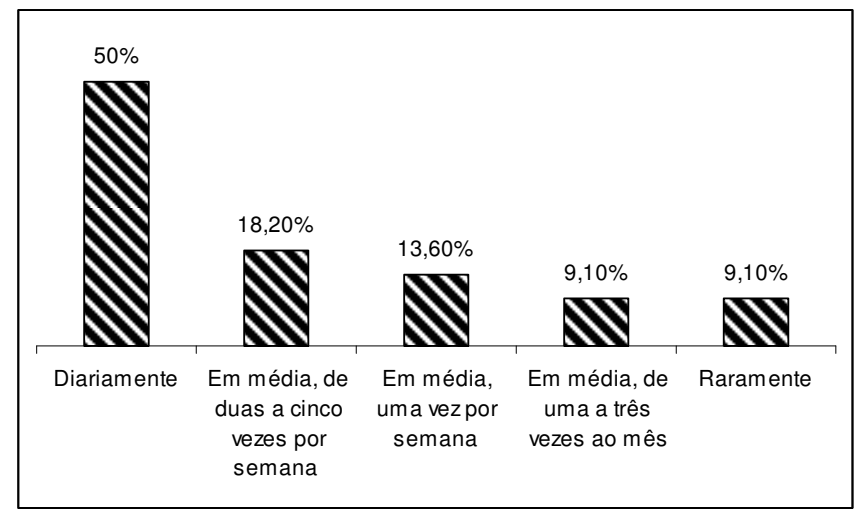

Gráfico 1. Percentual relacionado à frequência de uso do computador das alunas.

O computador é utilizado pelas alunas principalmente para a realização das seguintes atividades: estudo, digitação de trabalho, pesquisa, comunicação, registro de informações, trabalho, lazer e interação.

Além dessas atividades, realizadas a partir do uso do computador, 27,3\% das alunas utilizam o computador para o desenvolvimento de atividades na escola aonde 
trabalham, 40,9\% não utilizam o computador como recurso pedagógico e 31,8\% não trabalham em escolas.

As principais dificuldades apontadas para o uso do computador nas atividades escolares são a falta de computadores e de conhecimento sobre o computador. Segundo uma das alunas " $n$ a resolução de atividade ocorrem erros e aparecem dificuldades de resolver, pois não tenho conhecimento específico de computação". Além dessas dificuldades, outras apareceram, tais como:

a) dificuldade em trabalhar com as crianças muito pequenas;

b) falta de recursos;

c) utilização não adequada da tecnologia;

d) facilidade oferecida para os alunos fazerem cópia de trabalhos;

e) acesso a informações inadequadas;

f) uso inadequado do computador, sem relação com os conteúdos trabalhados em sala;

g) quantidade de informação disponível;

h) problemas técnicos;

i) falta de apoio das instituições;

j) falta de pessoal qualificado.

Por outro lado, as alunas também apontam as contribuições oferecidas pelo uso do computador no processo de ensino e aprendizagem. De modo sintético, para elas, o computador:

a) oferece outras possibilidades de interação;

b) permite o acesso a informações diversificadas de forma rápida;

c) desperta mais interesse das crianças pelas aulas;

d) possibilita a troca de informações;

e) amplia os espaço da sala de aula;

f) viabiliza a socialização de trabalhos através de outros meios;

g) prepara o aluno para o mercado de trabalho;

h) contribui com a inclusão digital dos alunos;

i) torna a aula mais interativa.

Segundo uma das alunas, o computador é "uma ferramenta que ajuda os alunos na construção do conhecimento, pois através dos softwares educativos e da pesquisa na internet o professor que os utiliza consegue ampliar o conhecimento de seus alunos".

A partir desses dados podemos identificar que há uma grande aproximação das alunas de Pedagogia com o computador, porém nem todas que são familiarizadas com essa ferramenta utilizam-na em atividades escolares. E isso não ocorre só por falta de infraestrutura, mas também por falta de conhecimentos técnicos e, principalmente, pedagógicos para utilização dessa ferramenta.

Esses são aspectos que reforçam a necessidade de cada vez mais inserir-se o uso das tecnologias no decorrer da formação dos professores para possibilitar a familiarização e a experimentação, bem como os estudos dos suportes teóricos e metodológicos para fundamentar o uso da tecnologia. Estas duas dimensões de inserção das tecnologias no processo de formação dos professores contribuiriam para consolidar o saber usar e como usar.

\section{Computador: uma máquina que provoca emoções e sentimentos}

As emoções "são complexos psicofisiológicos que se caracterizam por súbitas rupturas no equilíbrio afetivo de curta duração, com repercussões consecutivas sobre a integridade da consciência e sobre a atividade funcional de vários órgãos" (BALLONE, 2003, s/p). De outro modo, os sentimentos "são estados afetivos mais estáveis e 
duráveis, provavelmente provindos de emoções correlatas que lhes são cronologicamente anteriores" (IDEM, s/p).

Além disso, as emoções são manifestações que denunciam alterações decorrentes de estímulos internos e externos, visando conservar a vida e restabelecer o equilíbrio ou homeostase do organismo (BRUNO e MORAES, 2006).

Nesse sentido os sentimentos são estados psicológicos, portanto duradouros, enquanto a emoção é um estado fisiológico, na direção de dentro para fora do sujeito (SADALLA e AZZI, 2004). Essas mesmas autoras (2004, p. 344) destacam a noção de Ratey de que é "essencial compreender a emoção como um movimento de dentro para fora, um modo de comunicar os nossos mais importantes estados e necessidades internas".

Essas duas dimensões, de expressão e de estado humano, são importantes nos contextos escolares, pois é sabido que sentimentos e emoções podem estar relacionados à aprendizagem e aos fracassos escolares. Segundo Bruno e Moraes (2006, p. 55), "as situações vividas nos ambientes de aprendizagem podem fazer emergir emoções favoráveis ou desfavoráveis ao processo".

Do mesmo modo, eles podem influenciar na relação estabelecida entre o homem e a máquina, tendo em vista que são o pano de fundo das experiências vivenciadas. Nesse sentido, uma das questões investigadas nessa pesquisa são os sentimentos e emoções gerados a partir da relação das alunas com o computador.

Dentre os aspectos que apareciam nas aulas, nos momentos que eram utilizados o laboratório de informática, estavam a expressão de emoções e sentimentos provocados por esse contato. Algumas alunas expressavam satisfação e outras uma grande insatisfação, o que se relacionava frequentemente com o domínio ou não do manuseio do computador. Aquelas que se sentiam satisfeitas executavam as atividades e exploravam recursos além do que era proposto, enquanto aquelas que se sentiam insatisfeitas exaltavam as dificuldades técnicas e manifestavam o desejo de desistir e pouca tolerância com relação aos erros e problemas.

Além dessas questões observadas, outros sentimentos foram identificados a partir do questionário proposto. Alguns sentimentos e emoções apontados pelas alunas, advindos da relação com o computador, relacionavam-se com o prazer, o conforto, a satisfação, a criatividade, a organização, a praticidade, a alegria. Enquanto outros sentimentos se relacionavam com ansiedade, espanto e raiva.

Segundo uma das alunas "o uso da tecnologia para se comunicar pode trazer o sentimento de alegria, tristeza, mas também agitação e raiva quando se perde algum trabalho ou não se consegue fazer o que se quer".

Os sentimentos e emoções descritos por uma mesma pessoa eram diversos e variados, como a descrição de outra aluna "adrenalina de querer ver mais, conhecer mais, às vezes se torna um vício, amizade, descontração, irritação, indignação, tranquilidade, curiosidade, autonomia, liberdade, rapidez, facilidade”.

Diante disso podemos pensar no computador também como uma máquina capaz de provocar sentimentos e emoções diversos, e que de acordo com esses aspectos afetivos a aprendizagem pode tornar-se significativa ou não. Salienta-se, também, que o não-domínio da tecnologia, tanto por não saber manusear, como por não controlar todas as ações, não saber lidar com os imprevistos e erros técnicos, provocavam sentimentos e emoções desagradáveis.

As diversas emoções geradas momentaneamente contribuíam para a formação de sentimentos mais duradouros, os quais geravam resistências para o uso da tecnologia e preconceitos sobre as contribuições desses recursos. Essas resistências e preconceitos eram reforçados principalmente pelos discursos da falta de infraestrutura. Porém, o contato orientado por um professor em um contexto familiar de sala de aula, com o 
apoio dos colegas, favorecia que aos poucos as experiências fossem modificadas pelos resultados e produções proporcionados a partir do uso da tecnologia, como a construção de páginas web, blogs e webquests, ou seja, contribuíam com a formação de novas percepções e sentimentos sobre o uso da tecnologia.

Dessa forma, podemos resgatar as ideias de Vygotsky (1998) sobre a importância da afetividade para a aprendizagem e do aspecto social. Esse autor propõe a superação da dicotomia entre a dimensão cognitiva e afetiva. Tendo em vista que quando trabalhamos num contexto social, aspecto fundamental para a aprendizagem, este gera muitas emoções e sentimentos que emergem da relação com outros sujeitos e com objetos, seja pelas conquistas ou pelas dificuldades.

Assim, os aspectos afetivos trabalhados no decorrer da formação dos professores contribuem com a inserção das tecnologias nos processos de ensinar e de aprender. Quando proporcionamos o contato e experiências a partir do seu uso, exploramos o contexto social e o fundamentamos.

\section{Resultado e discussão}

As aulas foram desenvolvidas tanto em sala de aula como no laboratório de informática, utilizando recursos como sites de hospedagem de homepage gratuitos, software para gravação de áudio e o Ambiente Virtual de Aprendizagem (AVA) da Universidade. Evidencia-se a preocupação em utilizar recursos que podem ser utilizados posteriormente nas escolas, com o objetivo de oferecer possibilidades de introdução do uso construtivo de tecnologias nas escolas.

A partir da identificação de concepções sobre o uso das tecnologias nas escolas, muito focadas em experiências individualizadas, sem considerar um universo maior, foi proposta uma pesquisa para investigação das condições de infraestrutura das escolas, concepções de gestores, professores e alunos, bem como os modos como as tecnologias estão sendo utilizadas nas escolas.

A partir do compartilhamento dos dados coletados ficou evidente a grande variedade de concepções, usos e posicionamentos das escolas, o que dificultava fazer generalizações e contradizia a adoção de posturas rígidas sobre a questão.

Nas atividades de produção e criação de recursos na internet, inicialmente identificava-se um sentimento de incapacidade, como em frases como "isso é muito difícil e eu não sei mexer no computador. Não vou conseguir fazer". Porém, logo após a construção do blog, nos momentos de aula com apoio de colegas e do professor, as alunas passaram a reconhecer sua capacidade para lidar com esses novos recursos.

Também a produção da página na web e a publicação da WebQuest construída foram processos de grande envolvimento das alunas, nos quais uma aluna auxiliava a outra e o espaço do laboratório de informática tornou-se dinâmico e ativo. Tínhamos em alguns momentos queixas de que "assim eu não consigo" ou "desisto, não dá certo". Ao final, todas as duplas conseguiram fazer sua homepage e publicar a WebQuest. 


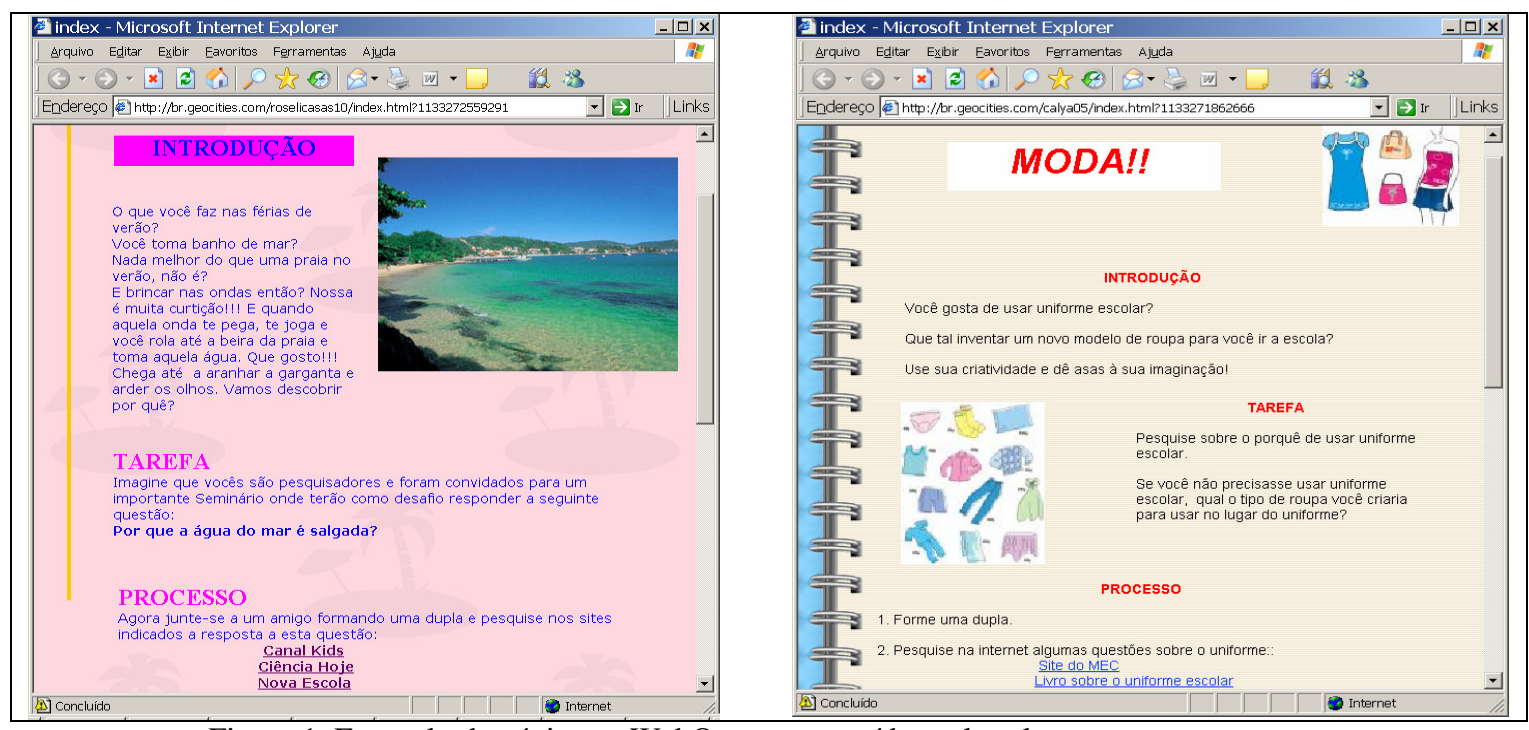

Figura 1. Exemplo de páginas e WebQuest construídas pelas alunas.

Este trabalho desenvolvido foi divulgado na página de curso e as alunas sentiram-se reconhecidas e mais capazes em lidar com os recursos do computador.

A avaliação do trabalho foi sendo realizada a partir da interação com as alunas, bem como a partir da observação dos comportamentos em sala, durante o processo. Alem disso, ao final do semestre foi aberto um espaço para avaliação de todo processo por meio de um fórum de discussão no ambiente virtual de aprendizagem, a partir do qual destacamos algumas contribuições postadas pelas alunas:

a. Quanto à disciplina de tecnologia educacional e aprendizagem penso que, é muito importante para ampliar um pouco o horizonte dos educadores ou futuros educadores, como nós (...) ela acrescenta e muito como trabalhar na prática em sala de aula de uma forma muito mais prazerosa e significativa para os alunos $e$ para os professores também (...)

b. A disciplina de Tecnologia Educacional vem contribuindo muito, pois, aprendemos que ela nos dá suporte em projetos e nos trabalhos com as crianças, desde que possua objetivos educacionais bem definidos para cada área contemplada. É um mundo mágico e maravilhoso.

c. (...) Percebemos que é de extrema necessidade que o professor conheça e utilize as diversas tecnologias, pois convivemos numa era informatizada em que a maioria das coisas está relacionada à tecnologia (...)

d. As aulas de tecnologia me fizeram refletir sobre certos aspectos que eu não havia pensado anteriormente (...) Percebi que quando praticamos, é quando aprendemos realmente, e é isso também, o que deve ser feito com nossos educandos.

e. (...) a nova visão que adquiri sobre as tecnologias e outros aprendizados proporcionados, como a criação do Blog, WebQuest, entre outros, é de que são recursos didáticos importantes para adaptar nos planos de aula e enriquecê-los.

f. As aulas de tecnologia nos trouxeram muitas informações e bases, para contribuir no aprendizado dos nossos alunos. E também para nós, alunas. Percebemos que com as aulas práticas no laboratório torna-se mais fácil, sendo que não tínhamos muita habilidade. Esperamos que todas as escolas de nosso País, um dia, possam vivenciar os usos de toda essa tecnologia que vem a avançar tão rapidamente (...)

g. Para mim foi importante o aprendizado de tecnologia, pois apesar de saber usar um pouco o computador, não tinha pensado em todas as atividades que foram mostradas para nós. Agora, ao falar em aula de tecnologia, com certeza já saberei o que dar como atividade (...) 
A partir das contribuições fica evidente que a proposta de uma disciplina para formação de professores para o uso das tecnologias educacionais precisa utilizar os recursos e compor-se por atividades práticas. Além disso, podemos perceber que os momentos da disciplina contribuíram para ampliar a visão do que seja tecnologia e permitiram visualizar possibilidades de uso dos recursos tecnológicos.

\section{Considerações finais}

A partir das impressões relatadas pelas alunas fica evidente que os pré-conceitos, sentimentos desagradáveis e resistências quanto ao uso relacionam-se com o desconhecimento das possibilidades oferecidas pelo computador e pela falta de domínio para o seu uso.

Diante disso, parece-nos fundamental o contato do aluno no decorrer de sua formação para posterior utilização das tecnologias nas suas atividades em sala de aula, tendo em vista que a partir da aproximação é possível experimentar, discutir, problematizar, fundamentar o uso da tecnologia, experimentar diversas emoções e construir novos sentimentos.

No decorrer da formação do professor a proposta de atividades e do estudo das tecnologias possibilita:

a) experimentar o uso da tecnologia com a mediação de um professor e de modo orientado e organizado;

b) discutir com o grupo de estudo as possibilidades, limites que o uso da tecnologia oferece em contextos escolares;

c) problematizar, identificando as dificuldades para o manuseio, os desafios para inclusão do uso da tecnologia de modo a contribuir com os processos de ensinar e aprender e a integração ao currículo;

d) fundamentar o uso da tecnologia a partir do estudo e aprofundamento teóricos, de modo a garantir a consistência e a qualidade na inserção dos usos das tecnologias na educação.

Sobretudo, destaco que a inserção do uso das tecnologias na formação dos professores contribui para que a escola responda aos desafios lançados pelos avanços tecnológicos e sua inserção na sociedade. Precisamos dar conta tanto da introdução das tecnologias na educação básica, para garantir o acesso e o domínio desses recursos, como na educação superior, para garantir uma formação adequada ao contexto social e à inserção do uso dos recursos tecnológicos nas diversas áreas de atuação profissional.

\section{Referências:}

BALLONE, G. J. Representação da Realidade. In: PsiqWeb, 2003. Disponível em $<$ http://www.psiqweb.med.br/cursos/repres.html >. Acessado em 13 mar. 2006.

BRUNO, Adriana R.; MORAES, Maria C.O enfoque da complexidade e dos aspectos afetivo-emocionais na avaliação da aprendizagem em ambientes online. In: SILVA, Marco; SANTOS, Edméa (Orgs.). Avaliação da aprendizagem em educação online. Loyola, 2006.

COZBY, Paul C. Métodos de pesquisa em ciências do comportamento. São Paulo: Atlas, 2003.

CYSNEIROS, Paulo G. Novas tecnologias no cotidiano da escola. In: $23^{a}$ Reunião Anual da ANPEd, 2000, Caxambu. Anais 23 ${ }^{\text {a }}$ Reunião Anual da ANPEd. Caxambu: ANPEd, 2000. Disponível em: <http://www.anped.org.br/23/23ra.htm>. Acessado em: 12 out. 2005.

DIAS, Cláudia Augusto. Hipertexto: evolução histórica e efeitos sociais. Ciências da Informação. Brasília, v. 29 n. 3, p.269-277, set./dez, 1999. Disponível em: 
$<$ http://www.scielo.br/scielo.php?script=sci_arttext\&pid=S0100-

$19651999000300004 \& \operatorname{lng}=$ pt\&nrm=iso $>$. Acessado em: 27 fev. 2006.

LEITE, Márcia C. Onde está a tecnologia no Curso de Pedagogia? In: $25^{a}$ Reunião Anual da ANPEd, 2002, Caxambu. Anais 25 Reunião Anual da ANPEd. Caxambu: ANPEd, 2002. Disponível em: <http://www.anped.org.br/25/25ra.htm>. Acessado em: 18 jan. 2006.

SADALLA, Ana Maria F. de A., AZZI, Roberta G. Contribuições da afetividade para a educação. In RIBEIRO DO VALLE, L.E.L. (Org.). Neuropsicologia e Aprendizagem. São Paulo: Robe Editorial, 2004, p. 343 - 354.

TAPSCOTT, Don. Geração digital: a crescente e irreversível ascensão da geração net. São Paulo: Makron Books, 1999.

VYGOTSKY, Lev. A formação social da mente: o desenvolvimento dos processos psicológicos superiores. Editora Martins Fontes, São Paulo, 1998. 